\title{
Dural incision in the petrosal approach with preservation of the superior petrosal vein
}

\author{
Irwan Barlian Immadoel Haq, MD, 1,2 Rahadian Indarto Susilo, MD,,2 Takeo Goto, MD, PhD,, and \\ Kenji Ohata, MD, PhD'
}

\begin{abstract}
'Department of Neurosurgery, Osaka City University Graduate School of Medicine, Osaka, Japan; and 'Department of Neurosurgery, Airlangga University Faculty of Medicine, Surabaya, Indonesia
\end{abstract}

\begin{abstract}
The petrosal approach has been applied for the treatment of many lesions in the posterior fossa, but the location and preservation of the superior petrosal veins (SPVs) during this approach are usually not particularly considered. The authors developed a technique of dural incision with special consideration of the location of the SPV to preserve venous flow during the petrosal approach. The authors describe technical details on how to cut the dura mater and superior petrosal sinus, with special attention to the location of SPV, so that the normal flow of the SPV to the lateral sinus can be preserved. Between July 2007 and March 2014, this technique was used in 45 patients, and no major complications were reported. The SPVs should be considered critical structures in the petrosal approach. Preoperative evaluation of the SPV anatomy should be performed in patients undergoing such surgical treatment, and the dural opening must be performed with special attention to the SPV to avoid intraoperative injury and postoperative complications.
\end{abstract}

http://thejns.org/doi/abs/10.3171/2015.3.JNS141618

KEY WORDS petrosal approach; superior petrosal vein; superior petrosal sinus; dural incision; surgical technique

$\mathrm{T}$ HE importance of preserving venous outflow when performing skull base surgery has been emphasized and recognized. ${ }^{4}$ Although the use of the petrosal approach has been widely reported, the location and preservation of the superior petrosal vein (SPV) are usually not given particular consideration in this context. ${ }^{1-3,7,16,28}$

The venous anatomy and its variations remain among the most crucial factors in the safety of the petrosal approach. ${ }^{25}$ In this approach, the tentorium and superior petrosal sinus (SPS) must be cut to gain a wider surgical field. Many authors have suggested cutting the SPS just before entering the sigmoid sinus. ${ }^{1,3,7}$ This technique has the risk of obstructing the venous flow of the SPV to the lateral sinus. Some authors have even recommended cutting the SPV during this approach. ${ }^{5,9}$ It has been reported that severing the SPV is a safe procedure and rarely causes problems, ${ }^{10,22}$ but several cases have been described in which neurological deficits developed after sacrifice of the SPV. ${ }^{15,17-20,29,30}$ A recent study described a rate of minor complications of $23 \%$ and a rate of major complications of almost $7 \%$ after an intraoperative SPV occlusion. ${ }^{17}$ A new technique was introduced in 2011 by Al-Mefty by applying the combined petrosal approach without cutting the SPS, but this technique is limited by a narrow working space under the tentorium along the posterior trajectory. ${ }^{20}$ In planning the petrosal approach, great consideration should be given not only to the vein of Labbé and the temporal venous drainage system but also to the SPVs. Opening the dura requires special skill, especially in dividing the SPS, preserving not only venous flow from the posterior temporal veins and the vein of Labbé but also the venous flow from the SPVs, if possible.

We report our technique of incising the dura and SPS with special attention to the location of the SPV so that the normal flow of the SPV to the lateral sinus can be maintained. Over the years, this technique has been used successfully by the senior author (K.O.) in a number of cases, and we believe that it is important to reintroduce it to the neurosurgical community. We discuss the advantages, limitations, and clinical implications of this technique and present an illustrative case to demonstrate its application.

\section{Methods}

Between July 2007 and March 2014, 62 patients underwent a petrosal approach in Osaka City University Hospital. In 45 of 62 patients, petrosal veins could be detected during the surgical procedures. Therefore, the petrosal ap-

ABBREVIATIONS IAC = internal auditory canal; SPS = superior petrosal sinus; SPV = superior petrosal vein.

SUBMITTED July 22, 2014. ACCEPTED March 20, 2015.

INCLUDE WHEN CITING Published online September 4, 2015; DOI: 10.3171/2015.3.JNS141618. 
proach with preservation of the SPV was applied in these 45 cases. In the other 17 cases, petrosal veins were already occluded by tumor involvement, and this technique was not required. The mean age of the 45 patients who were treated with the SPV-preserving technique was 58.2 years; $82.2 \%$ of the patients were women. The most common diagnoses were petroclival meningioma $(\mathrm{n}=25)$, craniopharyngioma $(n=12)$, trigeminal schwannoma $(n=4)$, pontine cavernoma $(n=2)$, and chordoma $(n=2)$. All patients underwent preoperative radiological evaluation with MRI and digital subtraction angiography. Before surgery, petrosal veins were radiologically detected in $20(80 \%)$ of the 25 patients with petroclival meningiomas and in all (100\%) of the patients with craniopharyngiomas, schwannomas, cavernomas, and chordomas. In 5 of the patients with petroclival meningiomas, preoperative images could not predict the existence of petrosal veins.

\section{Operative Technique}

Patient Positioning and Incision

After induction of general anesthesia, the patient is positioned in the lateral park bench position. The temporal region is kept in the horizontal plane (parallel to the floor), and the head of the table is elevated approximately $35^{\circ}$, resulting in a kyphotic curve in the upper thoracic and cervical regions of the spine. A periauricular skin incision and muscle elevation is performed.

\section{Craniotomy and Splitting Mastoidotomy}

An occipitotemporal bone flap involving the retrosigmoid and temporal regions is shaped. The outer table of the mastoid process is split. The outer table is saved by removing only the inner table by means of a high-speed drill until the posterior half of the entire length of the sigmoid sinus is exposed.

\section{Petrosectomy}

The sigmoid sinus is protected with a retractor, and then a retrolabyrynthine mastoidectomy exposure is performed with optimal skeletonization of the semicircular canal. The posterior part of the antrum is opened without exposing the ear ossicles. The dura mater is retracted posterior to the petrosal bone to expose the endolymphatic sac. The endolymphatic sac, which is relatively white in color compared with the surrounding dura mater, is identified and incised at the posterior surface of the petrosal bone. The petrosal ridge has already been removed up to the level of the internal auditory canal (IAC). The petrous apex resection is the key point in this approach, because it creates a smooth plane over the temporal bone down to the clivus. ${ }^{27}$ Several reports have demonstrated that partial removal of the bony labyrinth could be safely performed to allow increased petroclival and upper brainstem exposure while preserving normal hearing. ${ }^{6-14,23}$ Even if the canals are not opened, their bony canal should be identified for efficient petrosectomy.

\section{Dural Incision}

The middle fossa dura is opened along the inferior temporal lobe toward the SPS (Video 1).
VIDEO 1. Video clip demonstrating the petrosal approach with dural incision and preservation of the SPV. Copyright Irwan Barlian Immadoel Haq. Published with permission. Click here to view with Media Player. Click here to view with Quicktime.

The subtemporal dural incision is made as far anterior as possible, and its medial extent runs along the lateral margin of Meckel's cave (Fig. 1A). The presigmoid dura (Trautmann's triangle) is opened along the sigmoid sinus toward to the margin of SPS, paying great attention to the position of the SPV and its entry point to the SPS (Fig. 1B). The posterior fossa dura is opened, leaving $5 \mathrm{~mm}$ of dural fringe both along the anterior margin of the sigmoid sinus and along the inferior margin of the SPS. To perform transection of the SPS and the tentorium, first the point of insertion of the SPV is inspected, and then the SPS is transected as medially as possible, closely posterior to the trigeminal nerve to spare the SPV. The SPS is ligated with a clip at the medial side of the entrance of the SPV. The tentorium has been divided from the point of the transection of the SPS to its hiatus, right behind the dural entrance of the trochlear nerve (cranial nerve IV). Before cutting the tentorium, the trochlear nerve has to be identified by subtemporal route (Fig. 1B). Sectioning of the SPS in this medial side allows the SPS, the cerebellum, and the temporal lobe and its draining veins to be retracted as a unit. The SPV can be mobilized superioposteriorly with the SPS and thus be safely preserved and secured (Fig. 1C).

It is not necessary to expose the vein of Labbé for preservation, because the exposure itself may pose risk of damage. ${ }^{12}$ However, the sphenopetrosal sinus has to be identified during the dural incision at the base, and if it is remarkable, it must be preserved to prevent temporal venous congestion. ${ }^{11,12}$

\section{Case Illustration}

This 58-year-old woman presented with a 3-month history of progressive gait ataxia. Neurological examination was remarkable for left-sided limb ataxia and truncal ataxia. There were no cranial nerve abnormalities. Preoperative contrast-enhanced MRI revealed a broad-based lesion consistent with a left petroclival meningioma involving the cavernous sinus with marked brainstem compression (Fig. 2B). MR venography showed the location of the SPV and its entry point to the SPS. The patient underwent a combined petrosal approach with preservation of the SPV. Because the patient manifested no evidence of preoperative cranial nerve deficit from this cavernous involvement, the decision was made not to remove the intracavernous portion of the lesion. Postoperative MRI revealed removal of the posterior fossa component of the tumor, with the residual tumor within the confines of the cavernous sinus (Fig. $2 \mathrm{C}$ ). The patient had an uneventful postoperative course and was able to return to her regular level of activity.

\section{Results}

Patency of the petrosal vein was confirmed by Doppler flow measurement or indocyanine green video angiography at the end of each operation. Petrosal veins were preserved in all 45 cases. Postoperative MRI was performed in all cases and did not show any complication that might 

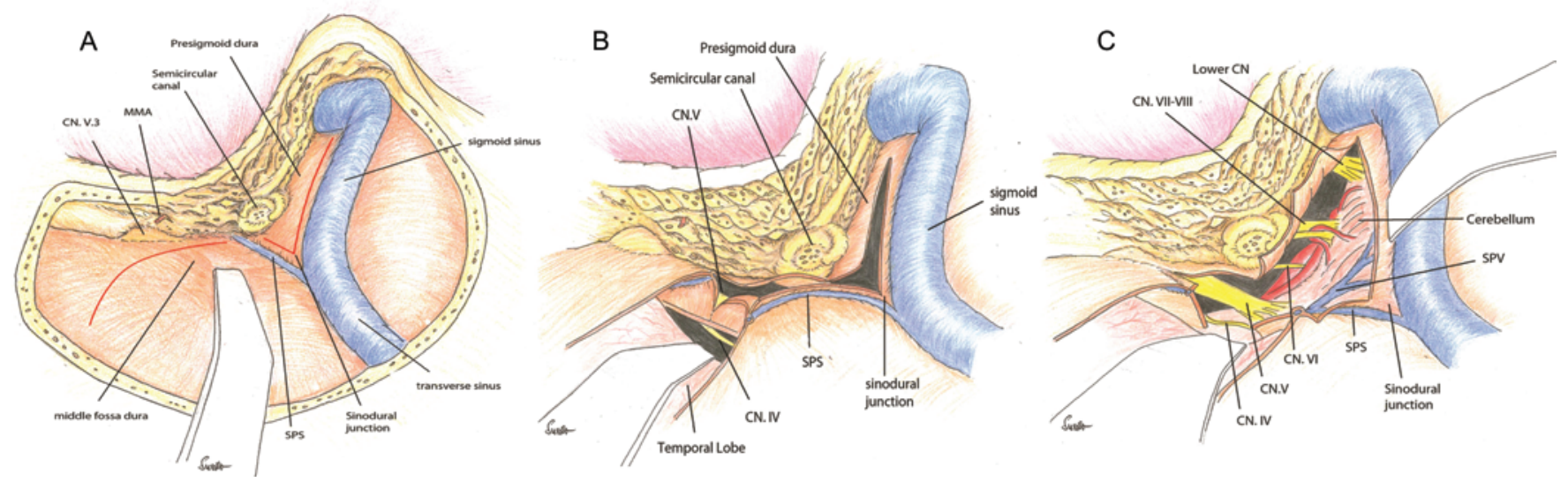

FIG. 1. Petrosal approach on the right side. A: Completion of the craniotomy and petrosectomy reveals the semicircular canal and presigmoid dura (Trautmann's triangle) bounded by the sigmoid sinus, SPS, and posterior semicircular canal. The red line indicates the site of the dural incision. B: The middle fossa dural incision is made as far anterior as possible along the inferior temporal lobe toward the SPS. The presigmoid dura is opened along the sigmoid sinus toward to the margin of SPS, leaving a 5-mm dural fringe along the anterior margin of the sigmoid sinus and the inferior margin of the SPS. C: Illustration of the completed dural incision. The point of insertion of the SPV is inspected, and the SPS is ligated with a clip at the medial side of the entrance of the SPV to spare this vein. The tentorium has been divided from the point of the transection of the SPS to its hiatus, right behind the dural entrance of the trochlear nerve. $\mathrm{CN}=$ cranial nerve; $\mathrm{MMA}=$ middle meningeal artery; $\mathrm{V} .3=$ mandibular division of trigeminal nerve. Copyright Irwan Barlian Immadoel Haq. Published with permission. Figure is available in color online only.

be associated with sacrifice of petrosal veins, such as cerebellar and brainstem edema, cerebellar venous infarction, cerebellar hemorrhage, brainstem hemorrhage, or hydrocephalus. Therefore, no postoperative CT venography or angiography was performed for evaluation of the patency of the petrosal vein. New-onset postoperative neurological deficits included diplopia in 4 patients, facial numbness in 3 , facial palsy in 3 , and hearing disturbance in 4 , but these
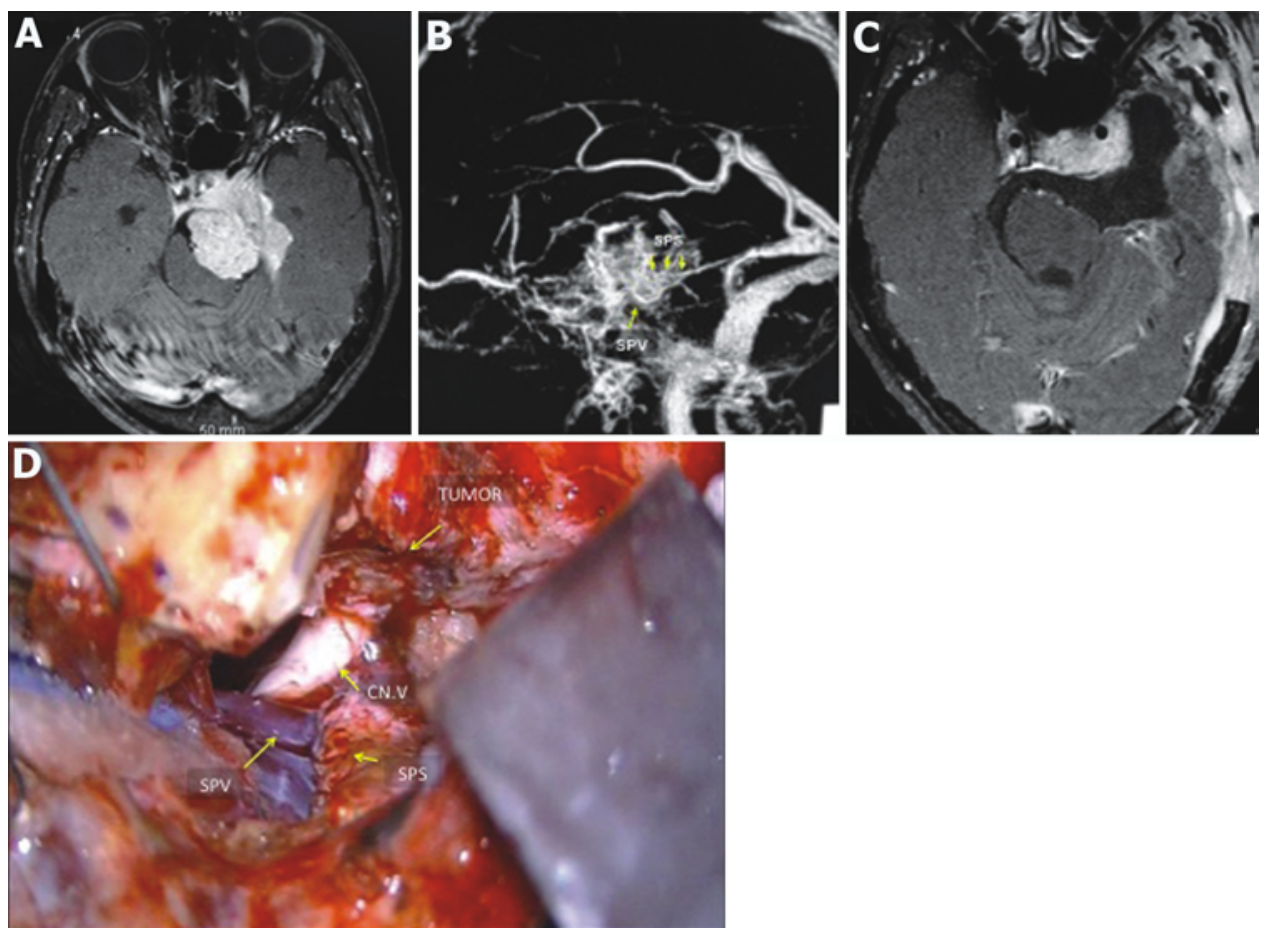

FIG. 2. A: Preoperative axial contrast-enhanced MR image obtained in a patient with a left petroclival meningioma involving the cavernous sinus. B: Preoperative MR venogram demonstrating the relation between tumor blush, the SPS, and the SPV. C: Postoperative axial MR image obtained after resection via the left combined petrosal approach. Reduction of tumor volume to the minimal residual amount in the cavernous sinus was achieved. D: Intraoperative photograph of the initial exposure following petrosectomy and dural incision with SPV preservation. Temporal extradural retractors are in place. The tumor is attached in the tentorium and petroclival region. Figure is available in color online only. 
deficits were caused by direct manipulation of the cranial nerves.

\section{Discussion}

In approaching the skull base, neurosurgeons have developed special surgical techniques to allow appropriate exposure with minimal brain retraction. The posterior petrosal approach was first described by Hakuba in the late 1970s and was popularized by Al-Mefty 10 years later. The presigmoid transpetrosal approach to tumors and vascular lesions of the petroclival and posterior cavernous sinus area is now well established. The petrosal approach provides an excellent pathway to the petroclival region and the posterior cavernous sinus. ${ }^{8}$ With the petrosal approach, retraction of the brain is minimal, and there is little possibility of injuring important superficial anastomotic veins, including the vein of Labbé. ${ }^{2}$ With further advances in skull base surgery, extension of the petrosal approach has become the key to accessing lesions in notoriously challenging regions, including petroclival meningiomas, $, 3,16$ retrochiasmatic craniopharyngiomas, ${ }^{1,2}$ giant upper basilar artery aneurysms, and brainstem lesions.

\section{Anatomy of the Venous Drainage System of the SPV}

The venous drainage of the SPV has many variations. These veins are among the largest and the most frequent veins in the posterior fossa. ${ }^{24}$ The SPVs drain the anterior and lateral surfaces of the brainstem, the petrosal surface, and some of the lateral parts of the tentorial and suboccipital surfaces. The SPV may be formed by the terminal segment of a single vein or by the common stem formed by the union of several veins. The most common tributaries of the SPV are the transverse pontine and pontotrigeminal veins, the common stem of the lateral group of the superior hemispheric veins, and the veins of the cerebellopontine fissure and the middle cerebellar peduncle. The anterior hemispheric veins, which drain the petrosal surface, and the veins from the brainstem commonly unite to form the SPVs, which empty into the SPS..$^{28}$ SPVs are subdivided into lateral, intermediate (rarest), and medial (most frequent) groups, based on the relationship of their site of entry into the SPS to the IAC. The intermediate group drains into the sinus above the IAC, the medial group drains into the sinus medial to the canal, and the lateral group drains in to the sinus lateral to the IAC. ${ }^{21,24} \mathrm{Af}-$ ter SPV obliteration, compensatory venous blood drainage seems to occur via anastomotic pathways directed to the ipsilateral supratentorial deep veins. Anastomoses to the contralateral petrosal vein system do not suffice to install an adequate outflow. ${ }^{8}$

\section{Clinical Implications of SPV Occlusion}

Inadvertent obliteration or compression of deep cerebral venous outflow has been among the major causes of brain damage following skull base surgery.,15 The importance of SPV preservation and possible postoperative complications after SPV obliteration during surgery has already been a matter of discussion. Differing advice on how to handle the SPV during skull base procedures can be found in neurosurgical literature. ${ }^{17,26,27}$
There are controversies in the literature surrounding the consequences of intraoperative obliteration of the SPV. The large anatomical variability of SPV is most likely responsible for the inconsistent occurrence of postoperative complications. ${ }^{11}$ It has been reported that severing of the SPV is a safe procedure and rarely causes problems, ${ }^{10,22}$ but several cases have been reported in which neurological deficits were developed after sacrifice of the SPV. These complications include contralateral hearing loss, transient postoperative cochlear nerve deficit, cerebellar and brainstem edema, cerebellar venous infarction, peduncular hallucinosis, cerebellar hemorrhage, brainstem hemorrhage, and hydrocephalus, leading in some cases to coma and death. ${ }^{15,17-20,29,30}$ In a recent study, Koerbel and colleagues ${ }^{17}$ describe a rate of minor complications of $23 \%$ and a rate of major complications of almost $7 \%$ after intraoperative SPV occlusion. None of the 27 patients with microsurgically treated petrous apex meningioma in whom the SPV complex was preserved showed any complication related to venous congestion, whereas after SPV obliteration minor complications occurred in 7 of 30 patients and major complications occurred in 2 patients, although not all of the morbidity was necessarily due to the SPV obliteration. Preservation of the SPV complex, especially when composed of large-caliber veins, should be attempted whenever possible to increase the safety of surgery. ${ }^{17}$

\section{Advantages and Limitations of This Technique}

Our dural incision technique does not add any significant difficulty for the neurosurgeon. The advantage of this technique is the potential decrease in the risk of postoperative venous complications such as venous infarction or hemorrhage.

Nevertheless, preservation of the SPV is not always possible during the petrosal approach. Tumors involving the petrous apex may encase the SPV. Therefore, the SPV sometimes has to be obliterated during this procedure because of its proximity, or even adherence, to the tumor.

\section{Conclusions}

The SPV should be considered a critical structure in the petrosal approach. Preoperative evaluation of the anatomy of the SPV can minimize intraoperative sacrifice and prevent subsequent postoperative complications. To avoid intraoperative injury to the SPV, dural opening must be performed with special attention to the SPV and its entry point to the SPS. Preservation of the petrosal venous complex, especially when composed of large-caliber veins, should be attempted whenever possible to increase the safety of surgery.

\section{References}

1. Al-Mefty O, Ayoubi S, Kadri PA. The petrosal approach for the resection of retrochiasmatic craniopharyngiomas. Neurosurgery 62 (5 Suppl 2):ONS331-ONS336, 2008

2. Al-Mefty O, Ayoubi S, Kadri PA: The petrosal approach for the total removal of giant retrochiasmatic craniopharyngiomas in children. J Neurosurg 106 (2 Suppl):87-92, 2007 
3. Al-Mefty O, Fox JL, Smith RR: Petrosal approach for petroclival meningiomas. Neurosurgery 22:510-517, 1988

4. Andeweg J: Consequences of the anatomy of deep venous outflow from the brain. Neuroradiology 41:233-241, 1999

5. Bogaev C, Sekhar LN: Petrocilval meningiomas, in Sekhar LN, Fessler RG (eds): Atlas of Neurosurgical Techniques. New York: Thieme, 2006, pp 695-710

6. Brandt MG, Poirier J, Hughes B, Lownie SP, Parnes LS: The transcrusal approach: a 10-year experience at one Canadian center. Neurosurgery 66:1017-1022, 2010

7. Cho CW, Al-Mefty O: Combined petrosal approach to petroclival meningiomas. Neurosurgery 51:708-718, 2002

8. Ebner FH, Roser F, Shiozawa T, Ruetschlin S, Kirschniak A, Koerbel A, et al: Petrosal vein occlusion in cerebello-pontine angle tumour surgery: an anatomical study of alternative draining pathways. Eur J Surg Oncol 35:552-556, 2009

9. Fukushima T: Manual of Skull Base Dissection, ed 2. Raleigh, NC: AF Neuro Video, 2004

10. Gharabaghi A, Koerbel A, Löwenheim H, Kaminsky J, Samii M, Tatagiba M: The impact of petrosal vein preservation on postoperative auditory function in surgery of petrous apex meningiomas. Neurosurgery 59 (1 Suppl 1):ONS68ONS74, 2006

11. Hafez A, Nader R, Al-Mefty O: Preservation of the superior petrosal sinus during the petrosal approach. J Neurosurg 114:1294-1298, 2011

12. Hakuba A: Surgical Anatomy of the Skull Base. Tokyo: Miwa Shoten, 1996

13. Hakuba A, Nishimura S: Total removal of clivus meningiomas and the operative results. Neurol Med Chir (Tokyo) 21:59-73, 1981

14. Horgan MA, Anderson GJ, Kellogg JX, Schwartz MS, Spektor S, McMenomey SO, et al: Classification and quantification of the petrosal approach to the petroclival region. J Neurosurg 93:108-112, 2000

15. Inamasu J, Shiobara R, Kawase T, Kanzaki J: Haemorrhagic venous infarction following the posterior petrosal approach for acoustic neurinoma surgery: a report of two cases. Eur Arch Otorhinolaryngol 259:162-165, 2002

16. Klimo P Jr, Browd SR, Pravdenkova S, Couldwell WT, Walker ML, Al-Mefty O: The posterior petrosal approach: technique and applications in pediatric neurosurgery. J Neurosurg Pediatr 4:353-362, 2009

17. Koerbel A, Gharabaghi A, Safavi-Abbasi S, Samii A, Ebner FH, Samii M, et al: Venous complications following petrosal vein sectioning in surgery of petrous apex meningiomas. Eur J Surg Oncol 35:773-779, 2009

18. Koerbel A, Wolf SA, Kiss A: Peduncular hallucinosis after sacrifice of veins of the petrosal venous complex for trigeminal neuralgia. Acta Neurochir (Wien) 149:831-833, 2007

19. Leonetti JP, Reichman OH, Silberman SJ, Gruener G: Venous infarction following translabyrinthine access to the cerebellopontine angle. Am J Otol 15:723-727, 1994

20. Masuoka J, Matsushima T, Hikita T, Inoue E: Cerebellar swelling after sacrifice of the superior petrosal vein during microvascular decompression for trigeminal neuralgia. J Clin Neurosci 16:1342-1344, 2009

21. Matsushima T, Rhoton AL Jr, de Oliveira E, Peace D: Microsurgical anatomy of the veins of the posterior fossa. J Neurosurg 59:63-105, 1983

22. McLaughlin MR, Jannetta PJ, Clyde BL, Subach BR, Comey $\mathrm{CH}$, Resnick DK: Microvascular decompression of cranial nerves: lessons learned after 4400 operations. J Neurosurg 90:1-8, 1999

23. Nishimura S, Hakuba A, Jang BJ, Inoue Y: Clivus and apicopetroclivus meningiomas-report of 24 cases. Neurol Med Chir (Tokyo) 29:1004-1011, 1989

24. Rhoton AL Jr: The posterior fossa veins. Neurosurgery 47 (3 Suppl):S69-S92, 2000

25. Sakata K, Al-Mefty O, Yamamoto I: Venous consideration in petrosal approach: microsurgical anatomy of the temporal bridging vein. Neurosurgery 47:153-161, 2000

26. Samii M, Matthies C: Management of 1000 vestibular schwannomas (acoustic neuromas): surgical management and results with an emphasis on complications and how to avoid them. Neurosurgery 40:11-23, 1997

27. Sekhar LN, Schessel DA, Bucur SD, Raso JL, Wright DC: Partial labyrinthectomy petrous apicectomy approach to neoplastic and vascular lesions of the petroclival area. Neurosurgery 44:537-552, 1999

28. Sincoff EH, McMenomey SO, Delashaw JBJ Jr: Posterior transpetrosal approach: less is more. Neurosurgery 60 (2 Suppl 1):ONS53-ONS59, 2007

29. Strauss C, Naraghi R, Bischoff B, Huk WJ, Romstöck J: Contralateral hearing loss as an effect of venous congestion at the ipsilateral inferior colliculus after microvascular decompression: report of a case. J Neurol Neurosurg Psychiatry 69:679-682, 2000

30. Strauss C, Neu M, Bischoff B, Romstöck J: Clinical and neurophysiological observations after superior petrosal vein obstruction during surgery of the cerebellopontine angle: case report. Neurosurgery 48:1157-1161, 2001

\section{Disclosure}

The authors report no conflict of interest concerning the materials or methods used in this study or the findings specified in this paper.

\section{Author Contributions}

Conception and design: all authors. Acquisition of data: Immadoel Haq, Susilo, Goto. Analysis and interpretation of data: Immadoel Haq, Susilo, Goto. Drafting the article: Immadoel Haq, Susilo. Critically revising the article: all authors. Reviewed submitted version of manuscript: all authors. Approved the final version of the manuscript on behalf of all authors: Immadoel Haq. Statistical analysis: Immadoel Haq, Susilo. Administrative/technical/ material support: Goto. Study supervision: Goto, Ohata.

\section{Supplemental Information Videos}

Video 1, Media Player. http://mfile.akamai.com/21490/wmv/ digitalwbc.download.akamai.com/21492/wm.digitalsource-naregional/jns14-1618_video_1.asx.

Video 1, Quicktime. http://mfile.akamai.com/21488/mov/ digitalwbc.download.akamai.com/21492/qt.digitalsource-global/ jns14-1618_video_1.mov.

\section{Correspondence}

Irwan Barlian Immadoel Haq, Department of Neurosurgery, Airlangga University/Dr. Sutomo General Hospital, Gedung Diagnosis Center (GDC) lantai 5, Prof. Dr Mustopo no. 6-8, Surabaya, East Java 60286, Indonesia. email: immadoelhaq@gmail.com. 